\title{
Economic performance of ground source heat pump: does it pay off?
}

\author{
Laura Gabrielli ${ }^{1, *}$, Michele Bottarelli ${ }^{2}$ \\ ${ }^{1}$ University of Ferrara, Italy \\ ${ }^{2}$ University of Ferrara, Italy \\ *Corresponding author. Tel: +39 0532 293671, E-mail: laura.gabrielli@unife.it
}

\begin{abstract}
A DCF model (discounted cash flow model) is implemented in order to investigate the economic aspects of GSHP (ground source heat pump) for heating and cooling, in comparison to traditional CB (condensing boiler). The DCF model allows the analysis of investment costs, operating costs and revenues of the two different systems in order to understand if the GSHP outperform its conventional counterpart in coming years, explicitly taking account for factors as price/cost growth. The whole analysis is performed adopting a parametric approach, in which all the previous terms are linked to energy labels, degree-days and EMRs (Energy Mix Ratios), the latter obtained as ratio between the full unit cost of electricity and natural gas paid by the householder. Relating to different EMRs, the DPBPs (Discounted Pay Back Periods) are presented in decision support matrixes in which energy labels and degree-days are the row/column variables, to confront the benefits of choosing between GSHP versus CB. Some considerations are also presented in order to express the environmental aspects. The results show that all higher energy labels have a good profitability ratio between costs and payback periods and demonstrate that GSHP system does pay off. Lower labels become interesting when the EMR drops to 0,25 and the gas price goes up $0,70 € / \mathrm{Nm}^{3}$.
\end{abstract}

Keywords: ground source heat pump, discounted cash flow models, energy mix ratio, decision support matrixes

\section{Introduction}

Heat pumps (HPs) are a reliable technology for space heating and cooling in commercial, industrial and residential buildings. In ground source heat pumps (GSHPs), the ground is used as heat source or sink; when compared to external air, it has smaller temperature variations during both heating and cooling season, and more advantageous thermal properties. For these reasons, GSHPs become an attractive alternative to conventional heating and cooling systems [1], owing to their higher energy utilization efficiency and reduction in greenhouse gases emission [2]. Economic evaluations were approached to exploit low temperature geothermal energy for buildings. In [3], the net present value is developed, showing a payback period of just a few years. Here, a discounted cash flow model (DFC) is implemented to assess the payback period for a GSHP application in comparison to traditional condensing boiler (CB), where the ground heat exchanger is the horizontal flat panel presented in [4].

\section{Methodology}

The goal is to calculate the payback period for a ground GSHP versus a CB, in connection with degree-days and energy building labels. The climate aspect and energy label are taken from the Italian law, but they can be easy extended to any other country setting different degree-days and energy requirements. To define the climate condition, a function was performed for the time series air temperature. Calibrating this function to obtain specific degree-days, it was possible to consider different climate zones. For both air conditioning systems it is supposed the same indoor distribution plant working at the same fixed low temperature $\left(44^{\circ} \mathrm{C}\right)$, keeping the analysis free from this part. The GSHP is supposed a vapor compression type heat pump coupled to a horizontal ground heat exchanger (Fig. 1). The CB is taken as boiler with high performance. For the GSHP, the coefficient of performance (COP) basically depends from the temperature at the evaporator, if the temperature at the condenser is taken fixed, like in this case. Anyway, the evaporator temperature is depending from the climate and the thermal behaviour of the HGHE and surrounding soil, so that this last 
behavior is the key to approach correctly the problem. A solution for the HGHE behaviour was fund implementing a numerical model in unsteady state, and adopting a combination of degree-days and energy requirements. The results was achieved forcing the behavior of an exchanger five meters long to reach on average $0{ }^{\circ} \mathrm{C}$ in the ground surrounding the exchanger, to exclude groundwater icing. The combination between degree-days and maximum power for exchanger unit length represents the limit that each other combination must respect. So, all the other cases were gathered as different combinations among climate zones and energy requirements. The thermal analysis has made all the results for next economic valuation. Here, installation and operation costs were considered to achieve a full price for unit building volume. The economic analysis was performed adopting different ratio between the full unit cost of natural gas and electricity, and their potential trend, to link the payback and pay off to an energy mix ratio (EMR). In the following sections, the former steps are reported to explain the approach.

\subsection{Building energy requirements and thermal behaviour}

The Italian law defines the limit for building energy requirements in heating $\left(E P_{i}\right)$, according to a country classification in seven degree-days climate zones $(A, B, C, D, E, F)$, and to a building shape ratio $(S / V)$. Moreover, the daily heating time is defined for each climate zone, but its observance is difficult to verify. The energy labeling weights the limit energy requirements to define eight energy classes $\left(a^{+}, b, c, d, e, f, g\right)$, adopting $K$ factors from 0,25 to 2,50 applied to $E P_{i}$. Generally, the heat exchange power $\left(\delta q_{V} / d t\right)$ in steady state and for unit volume can be estimated for a given thermal difference $d T$ occurred in time step $d t$, as:

$$
\frac{\delta q_{V}}{d t}=\frac{1}{V} \frac{\delta Q}{d t}=U \cdot \frac{S}{V} \cdot d T
$$

If its integral is extended to the full heating season, the product between $d T$ and $d t$ would represent the degree-days ( $d d)$ multiplied by the daily heating hours $(h h)$. If as $q_{V}$ it is taken $K^{*} E P_{i}$ for a given climate zone and shape ratio, the previous transmittance would give the global behaviour of the whole building, inclusive of all heat exchanges (heat transfer through shell, air ventilation, free heating, ...). So, it could be assumed as all-inclusive "equivalent transmittance”, and estimated as:

$$
\bar{U}=\frac{E P_{i}}{\frac{S}{V} \cdot d d \cdot h h}
$$

The former definition becomes usefully to approach heat transfer in a closed thermodynamic system by lumped parameters. Here, the building could be simplified in a homogenous body, whose internal energy variation occurs owing to the heat transfer belong its shell. The global mass is basically express only from walls, roof and foundation, because the air contribute is absolutely marginally. Knowing the building volume $(V)$, the average density $(\rho)$ and specific heat $(c)$, and the ratio $(r)$ between plenum over building volume, the integral of the energy balance between two time step becomes easy to do, assuming the air temperature independence from this heat exchange:

$$
r \cdot \rho \cdot V \cdot c \cdot d T=-\bar{U} \cdot S \cdot\left(T-T^{a i r}\right) \cdot d t \Rightarrow \int_{T_{0}}^{T} \frac{d\left(T-T^{a i r}\right)}{T-T^{a i r}}=-\int_{t_{0}}^{t} \frac{\bar{U} \cdot S}{r \cdot \rho \cdot V \cdot c} \cdot d t
$$


where $T_{0}$ is the indoor air temperature at time step $t_{0}$. The indoor temperature becomes also:

$T=T^{a i r}+\left(T_{0}-T^{a i r}\right) \cdot e^{-\bar{U} \cdot S \cdot\left(t-t_{0}\right)}$

When the air conditioning plant is turned off, the function (4) calculates the indoor air temperature in time related to the changing outdoor air temperature. When the plant is switched on, a constant target value for the indoor temperature can be assumed, and the heat of the air conditioning plant can be calculated by the equation (1). For simplicity, we assume the plant is able to reach the target temperature in a single time step. To generalize the climate zones, a time series for air temperature was defined, so that knowing its trend during days and seasons, the degree-days are known and also the energy requirements according to the former equation (4) and (1). The time series was conceptualized as a sinusoidal trend, representing the seasonal temperature variation for daily maximum and minimum temperature, with a smaller sinusoidal oscillation superimposed, representing the hourly temperature variation with a daily time shift. In Fig 4 the air temperature is showed for a whole year; for each other details we remand to [4], where the method is presented.

\subsection{Defining the Coefficient Of Performance for the heat pump}

According to the previous considerations, the minimum fluid temperature leaving the indoor circulating pump is set to $44^{\circ} \mathrm{C}$. Hence, it defines the temperature at the heat pump condenser, which can be supposed only few degrees higher $\left(46^{\circ} \mathrm{C}\right)$ than the first one, to perform suitably the heat exchange during condensation process. Neglecting the superheating after the evaporation and considering irreversibility coefficients to take into account the real processes, the thermodynamic cycle only depends from the temperature at the evaporator, which remain linked to the GHE. Therefore, even the COP only is depending to the fluid temperature leaving the GHE. It shouldn't drop too below $0{ }^{\circ} \mathrm{C}$ to exclude groundwater icing problem, and shouldn't go up $25 \div 30{ }^{\circ} \mathrm{C}$, to limit environmental effects. If we adopt the refrigerant R134a, the thermodynamic cycle is laid in the Pressure-Enthalpy chart, where it is easy to estimate working relationships between enthalpy and temperature. According to the Fig.1 and [5], we have estimated the most important functions for the working temperature supposed at the condenser $\left(46^{\circ} \mathrm{C}\right)$, whose saturated pressure is $1,20 \mathrm{MPa}$. The compressor work is defined by the adiabatic 12 and then correct with a irreversibility coefficient $\eta_{12}$. The heat exchange at the condenser can be calculated knowing $h_{2}$ and $h_{3}$, and adopting a heat transfer coefficient $\eta_{23}$. Here, the performance at the compressor and at the condenser are taken 0,85 both. So, the COP becomes i.e. 4,01/5,35 at $0 / 10{ }^{\circ} \mathrm{C}$. The expressions are reported in Fig. 2 and hold very high variances $\left(\mathrm{R}^{2}>0,96\right)$.

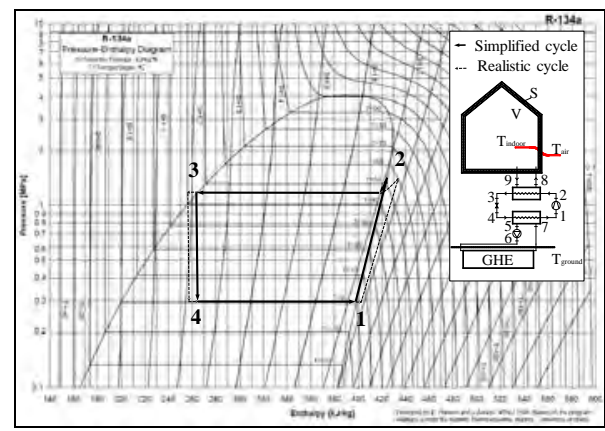

Figure 1: Thermodynamic cycle for R134a (E. Hansen \& I. Aartun, NTNU 1999)

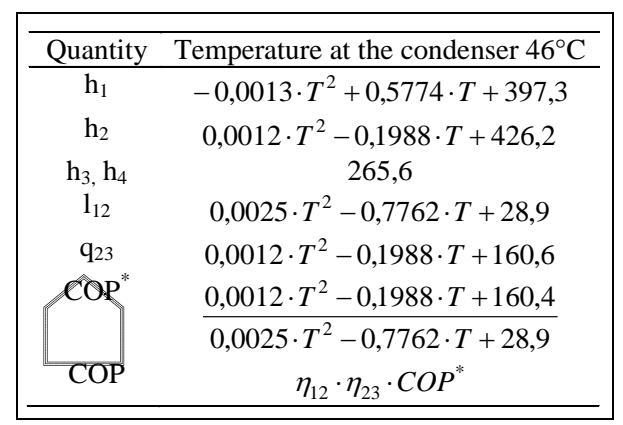

Figure 2: Relationships in temperature adopting R134a (ASHRAE Trans., 1988, vol.94) 


\subsection{Benchmark for geothermal outlet loop temperature}

The evaluation of the GHE performance was carried out as reported in [4]. There, the solution was conducted via the implementation of the unsteady-state three-dimensional numerical finite element code FEFLOW ${ }^{\circledR}$, which allows determining the groundwater flow and temperature fields in saturated/unsaturated porous media, considering both conductive and convective heat transport. The HGHE used herein consists in a flat panel $0.80 \mathrm{~m}$ high, $0.02 \mathrm{~m}$ wide and $5.0 \mathrm{~m}$ long, buried vertically in a trench $6.0 \mathrm{~m}$ long, $0.30 \mathrm{~m}$ wide and $2.49 \mathrm{~m}$ deep. The overall computational domain is subdivided into 23 horizontal layers (Fig. 4) and the groundwater flow was imposed parallel to the HGHE direction with a piezometric gradient of $0,2 \%$. The hydraulic and thermal properties attributed to the different materials constituting the domain (fluid within the panel, backfill, and surrounding soil) are assumed to be homogeneous are typical for sandy silts, bentonitic clay and water, within the ranges usually cited in [4]. Thermal boundary conditions are given at the soil surface in the form of a temperature time series, applying a coefficient at the previous sinusoidal function for air temperature, set to 0,6. The GSHP operation hours are selected to represent frequent working conditions, 5 AM - 9 AM and 5 PM - 10 PM from Monday to Friday, 7 AM - 11 PM on weekends. The heating operation is allowed from October $15^{\text {th }}$ to April $30^{\text {th }}$, the cooling from June $1^{\text {st }}$ to Septemebr $30^{\text {th }}$. During on time, the HP is activated in heating/cooling mode to maintain the indoor target temperature $\left(20 / 26{ }^{\circ} \mathrm{C}\right)$, supplying for each time step the heat estimated according (1) and (4). For simplicity, we assume that this heat and the related power is the same requested at the HGHE, and the compressor works only to raise it to the requested temperature. This hypothesis overrates the heat required from the HGHE for a rate linked to the heat pump COP at the working temperature. The flow rate into the HGHE is calculated for flushing water with $3{ }^{\circ} \mathrm{C}$ between the inlet and outlet temperature. To do so, a specific numerical loop was supplied directly from the FEFLOW's producer [6]; this is the most important difference with [4], where the inlet temperature was fixed to $4^{\circ} \mathrm{C}$ in heating and $35^{\circ} \mathrm{C}$ in cooling. The resulting temperatures are showed in Fig. 3, with two independent temperatures at 1,4 and 2,5 $\mathrm{m}$ deep from soil surface. The minimum temperature at the soil near the inlet reached almost $0{ }^{\circ} \mathrm{C}$ at $70^{\text {th }}$ day; no less temperature is accetable without icing problem. It means that no higher power is possible for this configuration, according to initial soil temperature, degree-days, energy requirements and type and length of HGHE. The maximum power was $36 \mathrm{~W} / \mathrm{m}$ in heating mode for each meter of HGHE; the medium one 27 $\mathrm{W} / \mathrm{m}$. The soil volume surrounding the HGHE whose temperature varies by more than $0,5{ }^{\circ} \mathrm{C}$ from initial condition is almost $80 \mathrm{~m}^{3}$.

The run for a full year needed very long computational time (more than six days). To avoid the time for running 29 cases, we examined each configuration according to the previous limit, and assuming the following hypothesis and observations:

1. the maximum heat extractable from the soil for heating time depends from the initial soil temperature and the maximum soil volume involved at same time;

2. the HGHE rate flow depends from the energy balance defined previously;

3. the HGHE outlet temperature for each different case can be estimate scaling the temperature time series resulting from the numerical solution for the limit case, using the difference between the two initial soil temperatures;

4. the difference of soil temperatures between two cases is equal to the difference of the yearly average air temperatures, because the sinusoidal functions are in phase;

5. the major or minor maximum power of a different case requires a proportional HGHE length for getting the same maximum power for unit length of limit case.

So, the heat transfer for each new case " $N$ ", only can be equal to that of the limit case " $L$ ": 
$c_{t} \rho_{t} V_{t} \cdot\left(\bar{T}_{i, N}^{\text {soil }}-\bar{T}_{f, N}^{\text {soil }}\right)+c_{w} \rho_{w} \dot{V}_{N}^{w} \Delta T_{e} \Delta t_{N}=c_{t} \rho_{t} V_{t} \cdot\left(\bar{T}_{i, L}^{\text {soil }}-\bar{T}_{f, L}^{\text {soil }}\right)+c_{w} \rho_{w} \dot{V}_{L}^{w} \Delta T_{e} \Delta t_{L}$

As the final energy state of the involved soil volume must be the same for both cases, even their final average temperatures must be the same $\left(\bar{T}_{f, N}^{\text {soil }} \equiv \bar{T}_{f, L}^{\text {soil }}\right)$, then, recording the phasing

$$
\begin{aligned}
& \left(\Delta t_{L} \equiv \Delta t_{N}\right): \\
& \dot{V}_{N}^{w}=\dot{V}_{L}^{w}+\frac{c_{t} \rho_{t} V_{t}}{c_{w} \rho_{w} \Delta T_{e} \Delta t_{L}} \cdot\left(\bar{T}_{N}^{a i r}-\bar{T}_{L}^{a i r}\right) \\
& T_{N}=T_{L}-\left(\bar{T}_{N}^{a i r}-\bar{T}_{L}^{a i r}\right) \cdot\left(1-\frac{t}{\Delta t_{L}}\right)
\end{aligned}
$$

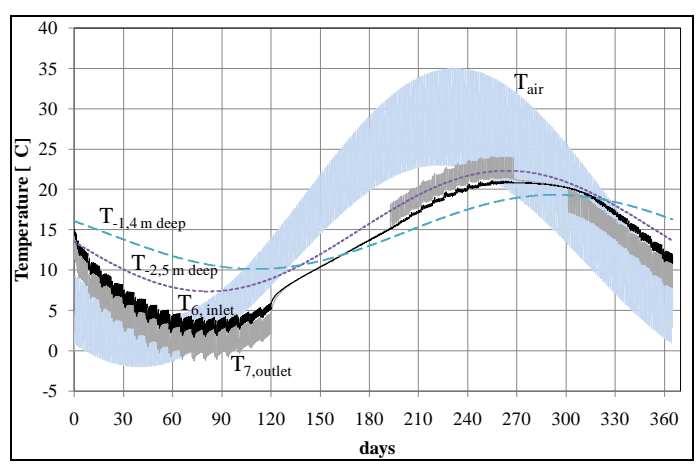

Figure 3: Time series for temperatures

\subsection{Pay back approach in Discounted cash flow analysis}

The economic analysis was undertaken using the discounted cash flow (DFC) approach in order to compare the different hypothesis. Typically the investment feasibility calculations are carried out using DCF where all the present and future inflows and outflows are discounted to obtain the net present value (NPV), the internal rate of return (IRR) or the discounted payback period (DPBP). The net present value represents the present value of all incomes and costs during the period of analysis of the investment. If the present value gives us a number larger than zero, then the project can be accepted. If the NPV is negative, the project must be rejected or modified. The IRR is the discount rate that makes the net present value equal to zero, so when the net present value of all costs equals the net present values of all incomes or revenues of the project. Usually the IRR must exceed the cost of capital. The discounted payback period for a project is the time it takes to recover the cost of investment. The cash flows are added up after taking account of the time value of money. The decision is based on comparing the different pay back periods with a predetermined cut off period decided by the decision maker. [7] In our analysis we considered the DPBP in order to verify if the GSHP pays off in comparison to a traditional heating system. To undertake the economic analysis, it needs to identify all the critical variables and assign appropriate values to them based on an analysis of the current market. The variables identified are listed in Tab. 1. Four scenarios $(1,2,3,4)$ where tested in order to consider the different cost of electricity and natural gas, which gives us a diverse energy mix ratio (EMR). The energy cost is expected to grow at a rate of $3 \%$ per year (in real term), inflation is considered at $2 \%$ per year. The rates were extrapolated considering the historical trends in the Eurozone [8]. To discount the future cash flows a weighted average cost of capital approach was used, considering a Debt/Equity ratio of $0.60 / 0.40$; the cost of debt is set at $5 \%$ and the cost of equity is assumed at $7 \%$. Sinking 
funds formula has been used to build up a sum of money to replace the systems after their usable life. The formula is:

$$
a=C i \frac{r}{q^{n}-1}
$$

Where $a$ is the annual deposit. The final value is used to replace the equipment at the cost $C i$. All costs were discounted considering an inflation rate plus a growth rate of energy costs, which gave us:

$$
C=\sum_{t=1}^{n} \frac{C_{t}(1+i+g)^{t}}{(1+r)^{t}}
$$

Where $C$ are the costs, $i$ is the inflation rate, $g$ is the growth rate, $r$ is the discount rate. The same approach was used by [3]. The discounted payback period is finally calculated as:

$$
D P B P=\frac{\left(C i_{G S H P}-C i_{C B}\right)}{\left(C_{E C B}-C_{E G S H P}\right)}
$$

where:

$\mathrm{Ci}_{G S H P}$ : cost of installment (or investment) for GSHP system;

$\mathrm{Ci}_{C B}: \quad$ cost of installment (or investment) for CB system;

$\mathrm{Ce}_{G S H P}$ : running costs (maintenance and electricity costs) for GSHP system;

\begin{tabular}{|c|c|c|c|c|c|c|c|c|c|}
\hline Description & Value & Units & Life cycle & Scenarios & $\mathrm{A}$ & $\mathrm{B}$ & $\mathrm{C}$ & $\mathrm{D}$ & Units \\
\hline Indoor circulating pump & 2,000 & $€ / \mathrm{W}_{\mathrm{e}}$ & 10 years & NATURAL GAS & 1,0 & 1,0 & 0,7 & 1,2 & $€ / \mathrm{Nm}^{3}$ \\
\hline GSHP & 0,700 & $€ / \mathrm{W}_{\mathrm{e}}$ & 15 years & ELECTRICITY & 0,5 & 0,25 & 0,175 & 0,24 & $€ / \mathrm{kWh}$ \\
\hline Stack & 0,100 & $€ / \mathrm{W}_{\mathrm{t}}$ & & EMR & 0,50 & 0,25 & 0,25 & 0,20 & \\
\hline CB cost of maintenance & 0,100 & $€ / \mathrm{m}^{3} *$ year & & INFLATION RATE ( i ) & $2 \%$ & $2 \%$ & $2 \%$ & $2 \%$ & $\%$ \\
\hline GSHP cost of maintenance & 0,010 & $€ / \mathrm{m}^{3}$ & & GROWTH (g) & $3 \%$ & $3 \%$ & $3 \%$ & $3 \%$ & $\%$ \\
\hline $\mathrm{CB}$ & 0,100 & $€ / \mathrm{W}_{\mathrm{t}}$ & 15 years & DISCOUNT RATE ( $\mathrm{r}$ ) & $5,50 \%$ & $5,50 \%$ & $5,50 \%$ & $5,50 \%$ & $\%$ \\
\hline Pollution check & 0,100 & $€ / \mathrm{m}^{3} *$ y ear & & & & & & & \\
\hline Major supply cost & 0,003 & $€ / \mathrm{W}_{\mathrm{e}}{ }^{*}$ year & & & & & & & \\
\hline GHE & 40,000 & $€ / \mathrm{m}$ & 30 years & & & & & & \\
\hline
\end{tabular}

$\mathrm{Ce}_{C B}$ : running costs (maintenance and natural gas costs) for CB system.

Table 1: Economic data

\subsection{Results}

The thermal analysis calculated all the necessary data to perform the economic analysis, adopting shape building ratio $S / V=0,5$ and excluding climate zone $A$ and energy labels $a+$ and $g$ of the Italian law, as they are very expensive or rare. In Tab. 2 are presented the most important entry data for calculating the payback period. In all next tables, data are given adopting energy labels $\left(a / b / c / d / e / f\right.$ as $0,37 / 0,63 / 0,88 / 1,13 / 1,50 / 2,13$ part of $\left.E P_{i}\right)$ and climate zones $\left(B / C / D / E / F\right.$ as $750 / 1150 / 1750 / 2550 / 3550$ degree-days) for rows and columns $\left({ }_{L}{ }^{Z}\right)$. The primary energy requirements are showed in Tab. 3 and 4, and from Tab. 5 to Tab. 8 payback periods are displayed for different scenarios (1/2/3/4). If we consider a predetermined cut off period of 30 years, in scenario 1 a large number of solutions overcame that period (indicated with $n c$ ). Considering a suitable payback for an householder of 10 years, all scenarios show that $a$ energy label is the best option, not depending from the EMR and the gas price. When 
we change the EMR from 0,50 to 0,25 keeping the gas price fixed into $0,7 \div 1,0 € / \mathrm{Nm}^{3}$, we can also include the $b$ label as good opportunity for the GSHP technology. In scenario 4 almost the solutions give positive results as quicker payback periods, excluding the worst energy label $f$, which do not perform in terms of recovering the initial investments. In Fig. 4 is showed the EMR given by natural gas price for EU27 and used in our scenarios to identify their equivalence with Europe countries. Finally, in Fig. 5 is reported the payback period related to the energy requirements for each scenario, excluding the energy label $f$, for which the Italian low forces a fixed energy requirements. The scenario 1 shows higher slope, which can be taken as sign of instability with energy requirements. The scenario 4 mirrors the opposite case, where the low slope reflects almost the independence between payback period and energy requirements.

Table 2: Climate zones variables, shape building ratio $S / V=0,5$

\begin{tabular}{ccccccc}
\hline Data & Unit & $B$ & $C$ & $D$ & $E$ & $F$ \\
\hline Daily heating hours & hours/day & 7.2 & 8.0 & 9.0 & 9.6 & 10.5 \\
Potential heating days & day/season & 200 & 200 & 200 & 200 & 200 \\
EP $_{i}$ & $\mathrm{kWh}_{\mathrm{t}} / \mathrm{m}^{3}$ year & 8.1 & 11.2 & 15.4 & 20.4 & 22.9 \\
Seasonal heating COP & - & 6.3 & 6.1 & 5.9 & 5.6 & 5.3 \\
\hline
\end{tabular}

Table 3: Electricity, $\mathrm{kWh} / \mathrm{m}^{3} \cdot$ year

\begin{tabular}{cccccc}
\hline${ }_{L}$ & $B$ & $C$ & $D$ & $E$ & $F$ \\
\hline \hline$a$ & 0.552 & 0.834 & 1.285 & 1.647 & 1.884 \\
$b$ & 0.949 & 1.442 & 2.194 & 2.825 & 3.230 \\
$c$ & 1.342 & 2.030 & 3.098 & 3.964 & 4.503 \\
$d$ & 1.742 & 2.641 & 4.016 & 5.148 & 5.833 \\
$e$ & 2.343 & 3.552 & 5.397 & 6.908 & 7.807 \\
$f$ & 3.396 & 5.146 & 7.784 & 9.959 & 11.182 \\
\hline
\end{tabular}

Table 5: Payback period, scenario 1

\begin{tabular}{cccccc}
\hline${ }^{Z}$ & $B$ & $C$ & $D$ & $E$ & $F$ \\
\hline \hline$a$ & 0 & 3 & 6 & 10 & 8 \\
$b$ & 4 & 9 & 13 & 20 & 18 \\
$c$ & 7 & 15 & 21 & nc & 31 \\
$d$ & 11 & 21 & 30 & nc & nc \\
$e$ & 17 & nc & nc & nc & nc \\
$f$ & 29 & nc & nc & nc & nc \\
\hline
\end{tabular}

Table 7: Payback period, scenario 3

\begin{tabular}{cccccc}
\hline${ }^{Z}$ & $B$ & $C$ & $D$ & $E$ & $F$ \\
\hline \hline$a$ & 0 & 3 & 5 & 7 & 6 \\
$b$ & 3 & 7 & 9 & 12 & 10 \\
$c$ & 9 & 10 & 12 & 15 & 12 \\
$d$ & 8 & 13 & 15 & 18 & 15 \\
$e$ & 11 & 17 & 18 & 21 & 17 \\
$f$ & 16 & 22 & 22 & 25 & 21 \\
\hline
\end{tabular}

Table 4: Natural gas, $\mathrm{Nm}^{3} / \mathrm{m}^{3} \cdot$ year

\begin{tabular}{cccccc}
\hline${ }_{L}{ }^{2}$ & $B$ & $C$ & $D$ & $E$ & $F$ \\
\hline \hline$a$ & 0.305 & 0.455 & 0.687 & 0.858 & 0.946 \\
$b$ & 0.524 & 0.788 & 1.174 & 1.473 & 1.622 \\
$c$ & 0.742 & 1.111 & 1.658 & 2.067 & 2.262 \\
$d$ & 0.964 & 1.446 & 2.150 & 2.686 & 2.931 \\
$e$ & 1.298 & 1.947 & 2.892 & 3.606 & 3.923 \\
$f$ & 1.883 & 2.824 & 4.174 & 5.202 & 5.621 \\
\hline
\end{tabular}

Table 6: Payback period, scenario 2

\begin{tabular}{cccccc}
\hline${ }_{L}{ }^{Z}$ & $B$ & $C$ & $D$ & $E$ & $F$ \\
\hline \hline$a$ & 0 & 3 & 4 & 7 & 5 \\
$b$ & 3 & 6 & 8 & 10 & 8 \\
$c$ & 5 & 9 & 10 & 12 & 10 \\
$d$ & 7 & 11 & 12 & 14 & 12 \\
$e$ & 10 & 14 & 14 & 16 & 13 \\
$f$ & 13 & 17 & 16 & 19 & 15 \\
\hline
\end{tabular}

Table 8: Payback period, scenario 4

\begin{tabular}{cccccc}
\hline${ }_{L}{ }^{Z}$ & $B$ & $C$ & $D$ & $E$ & $F$ \\
\hline$a$ & 0 & 3 & 4 & 6 & 5 \\
$b$ & 3 & 6 & 6 & 8 & 7 \\
$c$ & 5 & 8 & 8 & 10 & 8 \\
$d$ & 6 & 9 & 10 & 11 & 9 \\
$e$ & 8 & 11 & 11 & 12 & 10 \\
$f$ & 11 & 13 & 12 & 14 & 11 \\
\hline
\end{tabular}




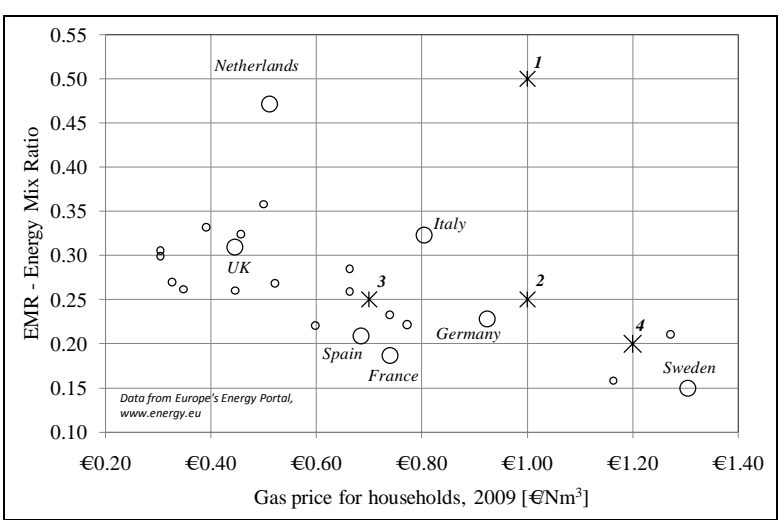

Figure 4: EMR given by gas price in EU27

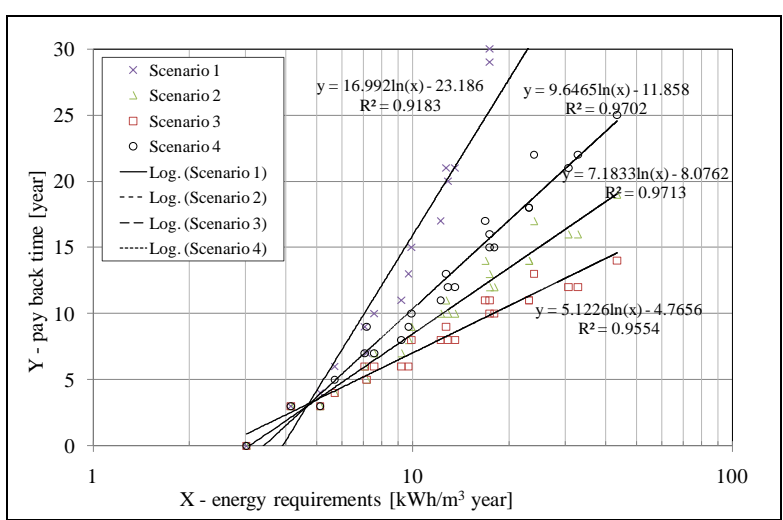

Figure 5: Regression analysis for the scenarios

\section{Conclusions}

We calculated the payback time for a ground source heat pump (GSHP) in comparison with a condensing boiler (CB), in connection with degree-days, energy building labels and an energy mix ratio (EMR), reflecting energy prices due to different combinations of primary energy. EMR is obtained as ratio between electricity and gas price. A numerical model was used to value the soil temperature modified from the HGHE, and this solution was scaled to approach the other combinations among climate zones and energy labels. The results show that all higher energy labels have a good profitability ratio between costs and payback periods, and demonstrate that GSHP system does pay off. Lower labels become interesting when the EMR drops to 0,25 and the gas price goes up $0,70 € / \mathrm{Nm}^{3}$. Further investigations should consider also environmental aspects (reductions of diffuse emissions, urban pollution control), potential raising energy label for retrofit action and different growth rate of energy price.

\section{References}

[1] A.D. Chiasson, Advances in modeling of ground-source heat pump systems, M. SC. Thesis, 1999, Oklahoma State University

[2] L. Rybach and W.J. Eugster, Sustainability aspects of geothermal heat pumps, Proceedings of $27^{\text {th }}$ Workshop on Geothermal Reservoir Engineering, 2002

[3] Kulcar B., Goricanec D. Krope J. Economy of exploiting heat from low-temperature geothermal sources using a heat pump, Energy and buildings, 40, 2008, pp. 323 - 329

[4] Bottarelli M., Di Federico V., Adoption of flat panels in soil heat exchange, Proceedings of $11^{\text {th }}$ World Renewable Energy Congress, 2010, pp. 330-335

[5] Y.A. Cengel, Termodinamica e trasmissione del calore, McGraw-Hill, $1^{\text {st }}$ Ed., 1998, pp. 659-663

[6] DHI-WASY GmbH, OpenLoop IFM Module, Copyright 2009, Berlin

[7] G. Brown, G. Matysiak, Real estate investment, a capital market approach, Prentice Hall, 2000

[8] Europe’s Energy Portal, 2010, www.energy.eu 